\title{
Immunological state of patients with carcinoma of the bronchus before and after radiotherapy
}

\author{
ANNE M SAVAGE, J A V PRITCHARD, T J DEELEY, AND B H DAVIES \\ From the South Wales Radiotherapy and Oncology Service, Velindre Hospital, Whitchurch, Cardiff, \\ and the Asthma Research Unit, Sully Hospital, Sully, South Glamorgan
}

ABSTRACT The immunological state of 30 patients with carcinoma of the bronchus was assessed before and after radiotherapy by lymphocyte response to PHA and E and EAC rosette formation.8 The results were compared with those from age-matched patients with benign chest disease and a음 group of healthy control subjects. Differences were found between the three groups and decreasedimmunological responses were found to correlate with shorter survival times for patients with $€$ cancer of the bronchus. These differences were not associated with the extent of the disease, or with the smoking habits of the patients. Significant differences in percentage EAC cell rosetting were $\vec{\infty}_{\infty}^{\circ}$ demonstrated between lymphocytes from patients with malignant disease $(31 \cdot 3 \pm 2 \cdot 0)$ and those for. control groups $(21 \cdot 5 \pm 1.9$ and $24 \cdot 0 \pm 2 \cdot 2)$. Cancer patients and benign chest disease patients both had significantly decreased mean $\mathrm{E}$ rosetting values $(59.3 \%$ and $55.6 \%$ ) compared with healthy control subjects $(69 \cdot 7 \%)$. The group of cancer patients with a normal percentage of $T$ lymphocyteso and total number of lymphocytes after radiotherapy, or those with low percentage EAC cell rosettes, $\frac{\mathscr{Q}}{\Phi}$ had a greater than $80 \%$ survival after seven months compared with less than $50 \%$ for the rest of the patients with carcinoma of the bronchus.

There have been many reports of a depressed immune response in patients with malignant disease, and also of decreased levels of immunologically responsive cells. ${ }^{1-4}$ Attempts to evaluate prognosis and survival have shown some degree of correlation with depressed values for in vitro tests, measuring numbers of immunologically active cells and their response to chemical or antigenic stimulus. ${ }^{5-7}$ Tests determining the immunological status of patients may be useful in monitoring the course of disease and the effects of treatment such as radiotherapy or chemotherapy. ${ }^{8-10}$ The relevance of results obtained using only one test of immunological competence has been questioned, ${ }^{11}$ and a more accurate overall assessment of the patient is obtained if results of several tests are considered. $^{12}$

In an attempt to assess the value of measuring immunological indices, a series of patients undergoing treatment for carcinoma of the bronchus was investigated to relate laboratory results with extent of disease and prognosis, and to determine whether treatment influences

Address for reprint requests: Dr BH Davies, Asthma Research Unit Sully Hospital, Sully, Penarth, South Glamorgan. immunological response when assessed by $\mathrm{E}$ and EAC rosetting and PHA blastogenesis.

\section{Methods}

Blood samples were obtained from 23 male and seven female patients (22 smokers) with carci-o noma of the bronchus, before and after radio-therapy. Blood was taken from 22 healthy donors (four smokers), and a group of $24 \frac{\mathrm{O}}{\mathrm{O}}$ patients (15 smokers) with benign chest diseases. These benign conditions included chronic bron- $N$ chitis, asthma, pulmonary fibrosis, pneumonia, and inactive tuberculosis. None of the patients sampled was receiving steroid therapy at the time.

The bronchogenic carcinoma patient groufe

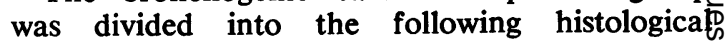
groups: 14 squamous cell carcinomas (three being well differentiated), one oat cell carcinoma and two anaplastic carcinomas.

Two patients had unidentified malignant his $\frac{\rho}{\Phi}$ tology and the histology of 11 of the carcinomas was unknown, since the diagnosis was made clinically and not confirmed histologically. It if possible that one patient had a metastasis fromp 
a primary tumour of the cervix.

At the time of treatment 10 patients had localised disease, 20 had widespread disease on scanning, and four of these had clinical evidence of secondary deposits.

Patients were treated by radiotherapy and received tumour doses ranging from 2400 to 3200 rads over four weeks, depending on the histology. Two patients were given palliative radiotherapy for brain metastases, receiving doses of 2000 and 2500 rads. One patient had been given chemotherapy before radiotherapy.

\section{LYMPHOCYTE SEPARATION}

Twenty $\mathrm{ml}$ of peripheral blood was taken by venepuncture and collected in lithium heparin tubes (Labco Ltd). Five $\mathrm{ml}$ aliquots of whole blood were layered onto $5 \mathrm{ml} \mathrm{Ficoll/Triosil} \mathrm{and}$ centrifuged at $400 \mathrm{~g}$ for 20 minutes. ${ }^{13}$ The white cell band was washed twice in TC199 (GibcoBiocult) followed by centrifugation at $300 \mathrm{~g}$ for 10 minutes. Cells were finally resuspended in TC199.

\section{LYMPHOCYTE RESPONSE TO}

\section{PHYTOHAEMAGLUTTININ (PHA)}

Lymphocytes were incubated at $37^{\circ} \mathrm{C}$ in TC199 buffered with $20 \mathrm{mM}$ HEPES (Hopkin and Williams Ltd) for 72 hours with and without PHA at a concentration of $1 / 20$ (Reagent grade, Wellcome Ltd); $1 \mu \mathrm{Ci}\left({ }^{3} \mathrm{H}\right)$ thymidine (Radiochemical Centre Ltd) was added 18 hours before harvesting.

\section{CULTURE CONDITIONS}

\begin{tabular}{|c|c|c|c|c|}
\hline & $\begin{array}{l}\text { Medium } \\
\text { TC199 }\end{array}$ & $\begin{array}{l}\text { Pooled } \\
\text { human }\end{array}$ & $\begin{array}{l}P H A \\
(1 / 20)\end{array}$ & $\begin{array}{l}\text { Lympho- } \\
\text { cytes }\end{array}$ \\
\hline $\begin{array}{r}\text { nstimu } \\
-\quad P H\end{array}$ & $\begin{array}{l}600 \mu 1 \\
525 \mu 1\end{array}$ & $\begin{array}{l}75 \mu 1 \\
75 \mu 1\end{array}$ & $\begin{array}{r}0 \mu 1 \\
75 \mu 1\end{array}$ & $\begin{array}{l}5 \times 10^{5} \\
5 \times 10^{5}\end{array}$ \\
\hline
\end{tabular}

Both unstimulated and PHA cultures were divided into three equal aliquots. Cells were cultured in triplicate in sterile polystyrene tubes (Nunc Ltd) and Terasaki plates (Sterilin Ltd) after the addition of $1 \mu \mathrm{Ci}$ isotope. Cells were harvested using a Minimash cell harvester (Dynatech Ltd) and the samples were counted on a $\beta$ counter using Instagel scintillant (Packard Instruments Ltd).

Results were expressed as distintegrations per minute (dpm). The stimulation index, which is the ratio of dpm in PHA cultures over dpm in unstimulated culture, and dpm with PHA presentcontrol dpm were quoted.

\section{ROSETTE FORMATION}

Sheep red blood cells (SRBC) rosettes were formed with separated lymphocytes using untreated SRBC in Alsever's solution (Tissue Culture Services) for $\mathrm{E}$ rosette estimation and complement-coated SRBC for EAC rosette estimation. ${ }^{14}$ This involved incubation of lymphocytes and SRBC for 10 mins at $37^{\circ} \mathrm{C}$ in the absence of serum. Rosettes were measured in triplicate for each lymphocyte sample after overnight incubation at $4^{\circ} \mathrm{C}$ and the mean value calculated.

\section{STATISTICAL ANALYSIS}

Mean values were calculated for results of immune tests for all groups and the standard error of the mean quoted in each case. Differences between means were tested for significance using Student's $t$ test and probabilities of $p<0.05$ are quoted. Life tables were calculated according to the method of Peto et $a^{15}$ and differences between these tested for significance using Logrank test. ${ }^{16}$

\section{Results}

Mean values for immunological tests for patients and control subjects are shown in table 1 . There are significant differences $(p<0.01)$ in percentage

Table 1 Mean values for immunological tests for patients and control subjects

\begin{tabular}{|c|c|c|c|}
\hline & Bronchogenic carcinoma & Benign chest disease & Healthy donors \\
\hline $\begin{array}{l}\text { Lymphocytes } \times 10^{-6} / \mathrm{ml} \text { whole blood } \\
\% \text { E rosettes } \\
\% \text { EAC rosettes } \\
\text { Absolute T lymphocytes } / \mathrm{ml} \\
\text { Absolute EAC cells } / \mathrm{ml} \\
\text { PHA SI } \\
\text { PHA dpm-control dpm } \\
\% \text { Null cells } \\
\% \text { E/EAC } \\
\text { Mean age }(y r) \\
\text { (range) }\end{array}$ & $\begin{array}{l}1 \cdot 27 \pm 0 \cdot 07 \\
59 \cdot 3 \pm 2 \cdot 0 \\
31 \cdot 3 \pm 2 \cdot 0 \\
7 \cdot 7 \pm 0 \cdot 5 \times 105 \\
4 \cdot 1 \pm 2 \cdot 0 \times 10^{5} \\
36 \cdot 3 \pm 8 \cdot 1 \\
19818 \pm 5044 \\
12 \cdot 6 \pm 2 \cdot 2 \\
2 \cdot 99 \pm 0 \cdot 39 \\
62 \\
(39-73)\end{array}$ & $\begin{array}{l}1 \cdot 24 \pm 0.13 \\
55 \cdot 6 \pm 2 \cdot 4 \\
24 \cdot 0 \pm 2 \cdot 2 \\
6 \cdot 4 \pm 0.6 \times 10^{5} \\
3 \cdot 0 \pm 0.4 \times 105 \\
15 \cdot 8 \pm 5 \cdot 1 \\
18184 \pm 1422 \\
20 \cdot 3 \pm 3 \cdot 4 \\
2 \cdot 57 \pm 0.23 \\
58 \\
(39-70)\end{array}$ & $\begin{array}{l}1.06 \pm 0.07 \\
69 \cdot 7 \pm 1.9 \\
21 \cdot 5 \pm 1.9 \\
8 \cdot 4 \pm 0.6 \times 10^{5} \\
2 \cdot 62 \pm 0.35 \times 10^{5} \\
67 \pm 27 \\
77344 \pm 27201 \\
10.5 \pm 2 \cdot 4 \\
4 \cdot 72 \pm 0.076 \\
32 \\
(18-61)\end{array}$ \\
\hline
\end{tabular}

E rosettes left overnight. 
EAC cell rosetting between lymphocytes from patients with malignant disease $(31 \cdot 3 \pm 2 \cdot 0)$ and those for control groups $(21.5 \pm 1.9$ and $24 \cdot 0 \pm 2 \cdot 2)$. Cancer patients and benign chest disease patients both had significantly decreased mean $\mathrm{E}$ rosetting values $(59.3 \%$ and $55.6 \%$ respectively) compared with healthy control subjects $(69 \cdot 7 \%)$. However, these differences were not obtained when absolute numbers of $\mathrm{T}$ cells and EAC rosetting cells were calculated, except for $T$ lymphocytes derived from chest disease patients $(p<0.05)$. Lymphocyte recovery from whole blood is significantly higher for patients with malignant and benign disease $(p<0.01)$. The mean percentage of null (nonrosetting) cells for each group was calculated by subtracting the sum of the percentage $E$ and EAC rosetting cells from 100 (table 1). Healthy control subjects and patients with malignant disease had significantly lower mean values than patients with benign chest disease $(p<0.05$ and $<0.01$ respectively).

However, if the mean ratio obtained by dividing percentage $E$ rosetting cells by percentage EAC rosetting cells is calculated (table 1) a significant difference can be demonstrated between both malignant and chest disease patient groups and healthy donors $(\mathrm{p}<0.05$ and $\mathrm{p}<0.01$ respectively), with the patients having a lower mean value than the healthy group.

Lymphocyte response to PHA was significantly depressed in chest disease patients $(15 \cdot 8 \pm 5 \cdot 1)$ compared with healthy donors $(67 \pm 27)$, but this could not be demonstrated for cancer patients. Results expressed as increase in $\mathrm{dpm}$ gave significant differences for both patient groups compared with control subjects $(p<0 \cdot 05)$.

There was no significant difference in mean $\mathrm{E}$ rosetting values between smokers and nonsmokers in the control groups, but lymphocyte response to PHA was significantly increased for smokers. A similar effect could also be demonstrated for patients with chest disease but not for patients with carcinoma of the bronchus where an elevated mean value for $\mathbf{E}$ rosetting cells could be shown. However, smoking did not affect significantly the mean $E$ rosetting value or response to PHA for any of the groups studied.

Table 2 shows the mean post-radiotherapy values when expressed as a percentage of each patient's pre-treatment values. A decrease of $50 \%$ occurred in the total number of lymphocytes, accompanied by a decrease of $47.5 \%$ in the absolute number of $T$ cells. The number of EAC rosetting cells decreased by $29.7 \%$. The mean percentage of $T$ lymphocytes was not affected by treatment. However, the mean per- $\stackrel{\vec{F}}{\stackrel{\vec{S}}{+}}$ centage of EAC rosetting cells increasd to $132 \%$ 응 of the mean pre-treatment value. When the 흐 stimulation index was calculated response to PHA was reduced to $30 \%$ after radiotherapy, $\stackrel{\mathbb{D}}{\varrho}$ only $9.6 \%$ was obtained if the increase in dpm was calculated.

The E/EAC ratio did not change significantly $\vec{\circ}$ after radiotherapy for patients with malignant $\vec{\omega}$ disease $(2.30 \pm 0.32$ after treatment compared to $\stackrel{\circ}{\circ}$ $2.99 \pm 0.39$ before treatment), and this was still $\vec{x}$ significantly different $(p<0.01)$ from the mean value for healthy controls $(4 \cdot 72 \pm 0 \cdot 76)$. Cancer $v$ patients were divided into two groups, those with ir histologically identified tumours (17), and those 8 with no definite histology (13). There were no을 significant differences between these groups for any of the immunological tests, either before or $\subseteq$ after radiotherapy. Similar results were also $₹$ obtained when mean test values for cancer $\vec{\omega}$ patients with localised disease and those of the $\mathscr{O}^{\circ}$ rest of the group were compared. The life tables calculated for patients with malignant disease are shown in the figure. Patients were divided into groups depending on whether they gave normal to high or abnormally low values in the $\frac{\circ}{\mathbb{D}}$ immunological tests when compared with healthy donors.

Immune measurements, which showed some differences between groups, were then combined to determine whether this further highlighted differences associated with survival.

A highly significant difference $(p<0.001)$ was obtained between patients with low percentage EAC rosettes and high percentage $T$ lympho- 3 cytes before treatment and those with high percentage EAC cell rosettes or low percentage $\mathrm{T}$ 욱 lymphocytes. There is also a significant difference $(\mathrm{p}<0.01)$ between patients with high percentage $T$ lymphocytes pre-treatment and high lympho- $\frac{D}{0}$ cyte recovery after radiotherapy and patients who have a decrease in either of these measure- $N$ ments. In both cases, patients with normal to $\mathrm{N}$ high values, when compared with control sub- 응 jects, had greater than $80 \%$ survival at seven

Table 2 Mean post-radiotherapy values as a percentage of patients' pre-treatment values

\begin{tabular}{lc}
\hline & Bronchogenic carcinoma \\
\hline Lymphocytes $/ \mathrm{ml}$ & $50 \cdot 1 \pm 4 \cdot 0$ \\
$\%$ T lymphocytes & $97 \cdot 2 \pm 4 \cdot 0$ \\
$\%$ EAC cell rosettes & $132 \cdot 2 \pm 13 \cdot 8$ \\
Absolute number T cells $/ \mathrm{ml}$ & $52 \cdot 2 \pm 5 \cdot 5$ \\
Absolute number EAC cells $/ \mathrm{ml}$ & $70 \cdot 3 \pm 12 \cdot 6$ \\
PHA SI & $30 \cdot 3 \pm 4 \cdot 9$ \\
PHA dpm-control dpm & $9 \cdot 6 \pm 2 \cdot 5$ \\
\hline
\end{tabular}




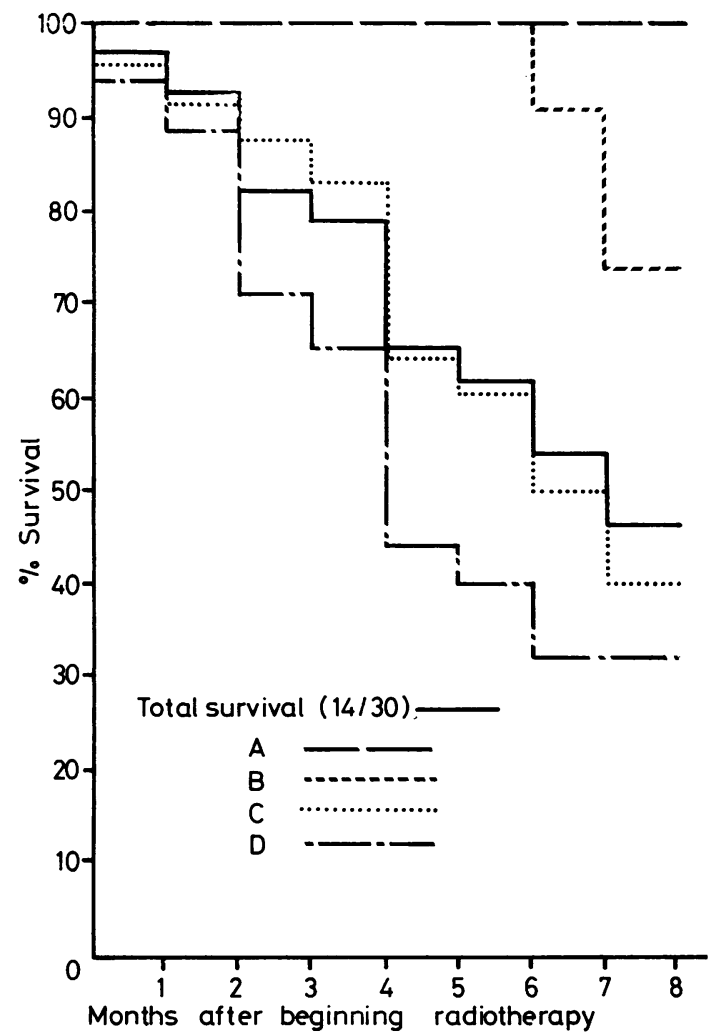

Figure Life table for patients with bronchogenic carcinoma having $(A)$ low $\% E A C$ cell rosettes and high $\%$ T lymphocytes (survival 6/6); (B) high \% $T$ lymphocytes and high lymphocyte recovery post $R T$ (survival 10/12); (C) high \% EAC cell rosettes or low \% T lymphocytes (9/24); (D) low \% $T$ lymphocytes or low lymphocyte recovery post $R T$ (6/18).

months and patients with low values had less than $50 \%$ survival for the same period. It therefore appears that a patient with high percentage $T$ lymphocytes and low percentage EAC cell rosettes before treatment followed by high lymphocyte recovery after radiotherapy has the best prognosis, with a greater than $80 \%$ chance of survival at seven months. There was no difference in survival between smokers and nonsmokers for patients with carcinoma of the bronchus.

\section{Discussion}

The differences in percentage rosetting cells between patients and control subjects reported in this investigation have not been observed in similar studies. However, significant changes in absolute number of $T$ lymphocytes but not relative proportions were reported. ${ }^{77-19}$ These differences were not obtained in this study because of a significant increase in lymphocyte recovery for carcinoma patients compared with healthy control subjects.

Since both malignant and benign disease groups show similar decreases in percentage $\mathrm{E}$ rosetting when compared with control subjects, it is not possible to use this measurement as an indication of the presence of malignant disease. However, determination of EAC rosetting cells is a more useful marker, since the mean value is significantly higher for the malignant disease group than either of the mean values for the benign disease and control groups. Although an increase in the proportion of EAC rosetting cells does not always correlate with an increased proportion of monocytes, an increase in the proportion of B lymphocytes is probably only partially responsible, and some monocyte contamination should be expected. Examination of mean percentage null cell values shows that differences in percentage EAC rosetting cells between benign chest disease patients and carcinoma patients may be associated with the increase in null cells for the benign group.

The use of the E/EAC percentage rosetting ratio demonstrates that the ratio of the different types of lymphocyte is more relevant when studying differences between patients and controls, since the two results are combined and not considered in icolation. The mean percentage EAC rosettes for chest disease patients is not significantly different from healthy control subjects. However, when the mean ratio of the E/EAC rosetting values for each patient in this group is compared it is significantly different from the mean value for control subjects.

Differences in response to PHA between patients and control subjects are more significant for chest disease patients than for patients with malignant disease. As such, this measurement would be of little use as an index of changes associated with malignant disease. The large variation in response of the healthy control subjects probably explains the lack of significance when the mean value for healthy donors is compared with the mean value for cancer patients.

Jerrels et $a l^{17}$ showed that between one-third and one-half of lung and breast cancer patients had decreased lympho-proliferative responses to at least one mitogen when PHA and concanavalin A were used. Wanebo et $a l^{18}$ demonstrated a significantly increased proportion of depressed 
PHA values when lung cancer patients were compared with healthy control subjects. A value was considered to be depressed if it was less than the value at the 10th percentile cut-off point of the control group mean value. If the cut-off point for the present investigation is taken to be twice the standard deviation lower than the mean control value then 21 out of 30 patients have depressed response to PHA, and this may be a more relevant way of expressing results.

The large decrease in cell numbers and response to PHA as a result of radiotherapy has also been obtained in other studies. After 3000 rads of mediastinal irradiation Byfield et $a l^{20}$ found that lymphocyte recovery was reduced to $45 \%$ of the pre-treatment value and the number of $\mathrm{T}$ cells was reduced to $43 \%$. EAC rosetting cells were reduced to $34 \%$ and reduced response to PHA for six patients. The reduction in numbers of EAC rosetting cells was much greater than found in this present series, but otherwise reductions are similar. Nordman and Toivanen ${ }^{21}$ showed $56 \%$ lymphocyte recovery and a PHA response reduced to $29 \%$ after radiotherapy accompanied by an approximately equal reduction in the number of $T$ and $B$ cells.

Results from this study have not demonstrated any immunological differences between carcinoma patients with differing histologies or extent of disease either before or after treatment, and this may be because of the small numbers involved.15 The relationship between low immunological test values and decreased survival demonstrated in this trial has also been observed by Wanebo and colleagues, ${ }^{18}$ who found significant differences between high and low values for absolute lymphocyte counts $(p<0.05)$ and response to PHA $(p<0.05)$ in lung cancer patients. Another study showed a significant correlation between response to DNCB and survival, and this was improved by adding the number of $T$ lymphocytes to the DNCB score. ${ }^{19}$ In this present study percentage $T$ lymphocytes and high percentage EAC cell rosettes taken in combination seem to be useful indices for predicting prognosis. After radiotherapy absolute lymphocyte numbers combined with pre-treatment percentage $T$ lymphocytes also showed differences which were significant $(\mathrm{p}<0.001)$.

Smoking did not have a significant effect on values obtained for any of the groups although there were some significant differences in mean values for certain immunological parameters between smokers and non-smokers. In this particular study smoking had no effect on patient survival, and it would appear that other dif- $\overrightarrow{\vec{F}}$ ferences between the control and patient groups $\frac{0}{0}$ outweigh the differences caused by smoking, and this single factor did not affect results for the total group significantly.

In conclusion, it can be stated that differences $\stackrel{\mathbb{D}}{2}$ exist between patients with chest disease and is healthy control subjects, but the immunological $\overrightarrow{0}$ characteristics of malignant disease cannot be separated easily from those of benign chest $\vec{\omega}$ disease using generally accepted tests of immunological responsivness. Therefore, we suggest $x$ that the comparison of immunological test $\stackrel{\omega}{\sim}$ results for patients with carcinoma of the $v$ bronchus with those for patients with benign chest disease are of little value as indicators of malignant disease, except perhaps in the case of EAC rosetting.

The effects of radiotherapy have been fairly well defined by previous authors and results presented in this paper confirm their findings, $\infty$ although there is a possible difference in EAC. rosetting cell losses after treatment.

Immunological studies are more relevant when applied to survival, since there is considerable correlation between immunological test results and decreased survival for the three para- $\mathbb{Q}$ meters studied. These changed immunological $\overrightarrow{\hat{O}}$ values may be a useful indicator of those 3 patients who may give a more positive response to a certain type of treatment, when combined with other relevant clinical information. It has also been demonstrated that some values after 을 radiotherapy can be correlated with survival, $\underset{\otimes}{x}$ which may reflect response to treatment.

We would like to thank Tenovus and South Glamorgan Area Health Authority for financial support.

\section{References}

1 Garrioch DB, Good RA, Gatti RA. Lymphocyte $\widetilde{N}$ response to PHA in patients with non-lymphoid $N$ tumours. Lancet 1970; 1:618.

2 Herberman RB. Immunologic approaches to the $\mathrm{\omega}$ diagnosis of cancer. Cancer 1976; 37:54-61.

3 Jenkins VK, Ray $P$, Ellis HN, Griffiths CM, Perry RR, Olson MM. Lymphocyte response in $\frac{\digamma}{\Phi}$ patients with head and neck cancer. Arch Oto- $\stackrel{\mathcal{S}}{+-}$ laryngol 1976; 102:596-600.

4 Hadfield TL, Marcus S, Smart CR, Plenk HP. Significance of $T$ and $B$ lymphocyte counts and $\overrightarrow{\mathbb{D}}$ function test in anti-cancer therapy. Int $J$ Radiat $\frac{\varrho}{\mathbb{D}}$ Oncol Biol Phys 1977; 2:73.

5 Riesco A. Five year cancer cure: relation to total amount of peripheral lymphocytes and $\Omega$ neutrophils. Cancer 1970; 25:135-40. 
6 Chretien PB, Crowder WL, Gertner HR, Sample WF, Catalona WJ. Correlation of pre-operative lymphocyte reactivity with the clinical course of cancer patients. Surg Gynecol Obstet 1973; 136: $380-4$.

7 Dellon AL, Potvin C, Chretien PB. Thymus dependent lymphocyte levels in bronchogenic carcinoma. Cancer 1975; 35:687-94.

8 Raben $M$, Walach $\mathbf{N}$, Galili $H$, Schlesinger $M$. The effect of radiation therapy on lymphocyte sub-populations in cancer patients. Cancer 1976; 37:1417-21.

9 Wood SE, Campbell JB, Anderson JM. Lymphocyte response after radiotherapy. Lancet 1974; 1:863.

10 Roth JA, Eilber FR, Morton DL. Effect of adriamycin and high-dose methotrexate chemotherapy on in vivo and in vitro cell-mediated immunity in cancer patients. Cancer 1978; 41: 814-9.

11 Deegan MJ, Coulthard SW, Qualman SJ, Schork MA. A correlative analysis of in vitro parameters of cellular immunity in patients with squamous cell carcinoma of the head and neck. Cancer Res 1977; 37:4475-81.

12 Catalona WJ, Tarpley JL, Potvin C, Chretien PB. Correlations among cutaneous reactivity to DNCB, PHA-induced lymphocyte blastogenesis and peripheral blood $\mathrm{E}$ rosettes. Clin Exp Immunol 1975; 19:327-33.

13 Bøyum A. Isolation of leukocytes from human blood. Scand J Clin Invest 1968; 21: suppl 97,
9-29.

14 Anthony HM, Kirk JA, Madsen KE, Mason MK, Templeman GH. E and EAC rosetting lymphocytes in patients with carcinoma of the bronchus. Clin Exp Immunol 1975; 20:29-40.

15 Peto R, Pike MC, Armitage $P$ et al. Design and analysis of randomised clinical trials requiring prolonged observation of each patient. $\mathrm{Br} J$ Cancer 1977; 35:1-39.

16 Mantel N. Evaluation of survival data and two new rank order statistics arising in its consideration. Cancer Chemother Rep 1966; 50:163-70.

17 Jerrels TR, Dean JH, Herberman RB. Relationship between $\mathrm{T}$ lymphocyte levels and lymphoproliferative responses to mitogens and alloantigens in lung and breast cancer patients. Int J Cancer 1978; 21:282-90.

18 Wanebo HJ, Rao B, Miyazawa $\mathrm{N}$ et al. Immune reactivity in primary carcinoma of the lung and its relation to prognosis. $J$ Thorac Cardiovasc Surg 1976; 72:339-50.

19 Concannon JP, Dalbow MH, Eng CP, Kline L. The clinical significence of various tests of immune competence in patients with lung cancer. Int J Radiat Oncol Biol Phys 1977; 2:34.

20 Byfield PE, Stratton JA, Small R. Lymphocyte response after radiotherapy. Lancet 1974; 1:309.

21 Nordman E, Toivanen A. Effects of irradiation on the immune function of patients with mammary, pulmonary or head and neck carcinoma. Acta Radiol Onc Rad Phys Biol 1978; $17: 3$. 